\title{
ANALYSIS OF EN IMPEDANCE SPECTRA FOR DETERMINATION OF CORROSION- RELATED DIFFUSION EFFECT ON BARRIER PROPERTIES OF Zn AND AI PIGMENTED EPOXY COATINGS
}

\author{
Boleslav EREMIÁŠ ${ }^{1}$, Lubomír MINDOŠ ${ }^{1}$, Libor TUREK ${ }^{1}$ \\ 1SVUOM Ltd., Praha, Czech Republic, EU, eremias@svuom.cz
}

https://doi.org/10.37904/metal.2021.4170

\begin{abstract}
The effect of different vol. \% Zn:Al ratio in $\mathrm{Zn}$ and Al pigmented epoxy coatings with the same OPVC (40 vol. $\%$ ) has been investigated by means of $\mathrm{EN}$ measurements performed in $0.05 \mathrm{M} \mathrm{NaCl}$ for $168 \mathrm{hrs}$. Analysis of EN data in frequency domain permits to evaluate changes of the noise impedance spectra due to possible contributions from charge transfer and mass transport reactions occurring in pores filled with corrosion products and at the delaminated areas of tested coatings. The interpretation of EN noise impedance spectra for determination of water penetration and the loss of adhesion in combination with the single frequency (1 $\mathrm{kHz}$ ) impedance test results for tested coatings has also been discussed.
\end{abstract}

Keywords: Painting system, Zn pigment, Al pigment, electrochemical noise analysis, delamination of coating

\section{INTRODUCTION}

Opposite with epoxy zinc rich coatings (ZRP) the modified type of ZRP with partial substitution of Zn by Al have not yet been widely studied. For some exceptions can be considered recently published articles on the use of ENA for characterization of these types' coatings regarding to delamination kinetics of underlaying steel [1 - 3]. In all of them for noise impedance spectrum interpretation similarity of those characteristics with simulated electrochemical impedance spectrum (EIS) for coated steel is accepted [4] and it was used to provide information about disbonded region of the coating/steel interface.

This approach to electrochemical characterisation of tested coating systems protective performance can be supplemented by analysis of EN data with implementation of a modified noise resistance $R_{n}{ }^{*}$ and noise resistance $R_{n}$ values [5]. According to Bierwagen et al [5] the value of the difference between these noise resistance values may give an estimation of the degree of imperfections in a coating. For $\mathrm{Zn}$ and $\mathrm{Al}$ pigmented epoxy coatings with low OPVC (40 vol. \%) and different vol. \% ratio $\mathrm{Zn}$ :Al the relation of parameter $\mathrm{R}_{n}{ }^{*}-\mathrm{R}_{n}$ to oxygen reduction reaction (ORR) occurring on $\mathrm{Zn}$ particles in the coating can be important for understanding of a barrier mechanism and optimising coating formulation. Implementation of this parameter into the noise impedance spectrum interpretation as well as parameters related to changes in the resistive properties seems to be necessary for better understanding of key factors affecting protective performance of the mentioned above type of coatings. Considering possible similarity of MEM impedance spectrum obtained by use of ENA with simulated EIS plots for ZRP the work of Vilche et al [6] offers some possibilities of application for given purpose. It should be noticed these authors successfully simulated EIS plots for ZRP by the transfer function which involves the constant phase element $C P E=\left[C(i \omega)^{\alpha}\right]^{-1}$ with a parameter $\alpha=0.4-0.6$. In addition to it a finite diffusion impedance was considered to account for the transport process through the coating together with the charge transfer resistance of the $\mathrm{Zn}$ dissolution process occurring in parallel with ORR. In this case parameter $R_{n}{ }^{*}-R_{n}$ can possibly be used in terms including the charge transfer resistance $R_{A}$ of this process in the coating according to Vilche et al model. 
The main aims of this study were so checking of this possibility and verifying how accurately a new approach to noise impedance spectrum interpretation can help to distinguish differences in the protective performance of tested coating systems. Apart from electrochemical measurements more advanced microscopic method was used for metallographic analysis of tested coating systems after immersion tests. EDX mapping and structure (SEM - SE image) of cross-sections were chosen for this purpose.

\section{EXPERIMENTAL}

\subsection{Materials}

Two types of modified Zn pigmented epoxy coatings were prepared using $\mathrm{Zn}$ and Al pigments (see Table 1) with the same value of OPVC $=40$ vol. \% and different vol. \% of $\mathrm{Zn}: \mathrm{Al}$ ratio.

Table 1 Characteristic of ZRP modified with Al additions

\begin{tabular}{|c|c|c|c|c|c|}
\hline Sample & $\begin{array}{c}\text { OPVC } \\
\text { (vol\%) }\end{array}$ & $\begin{array}{c}\text { Zn:Al ratio } \\
\text { (vol\%) }\end{array}$ & Filler & Binder & Hardener \\
\hline AKAl 112 & 40 & $88: 12$ & Alum.Stapa 2NL & Epicote 1010 & Epicure 3115 \\
\hline AKAI 107 & 40 & $94: 6$ & Alum.Stapa 2NL & Epicote 1010 & Epicure 3115 \\
\hline
\end{tabular}

Zn dust for preparation of coatings was 4P16 (supplied by UMICORE Zinc Alloys and Chemicals Co.). In combination with Zn dust aluminum paste Alum.Stapa 2NL (supplied by ECKART GmbH) and also the same type of binder and hardener (supplied by Momentive Co.) were used. In order to avoid the particle sedimentation and for better dispersion ion-exchangeable inorganic pigment Syloid 244 based on synthetic amorphous silica was used in both types of tested coatings.

Both tested coatings were applied by a spreader bar to steel C4Q panels previously polished and degreased. The average thickness of dry film was $55 \mu \mathrm{m}$ for tested coatings.

\subsection{Method}

Immersion tests using ENA for tested coatings on steel substrate specimens were performed with use of the same experimental set-up as described earlier [7]. The potential and current noise (ENP and ENC) values (for given data set measured for given immersion time) were collected for measurement periods of $600 \mathrm{~s}$ with sampling rate of $20 \mathrm{~Hz}$ (12000 points for period) using GAMRY ESA 410 software in the end of $168 \mathrm{hrs}$ exposure test in $0.05 \mathrm{M} \mathrm{NaCl}$. These data were used to obtain MEM Noise Impedance Spectrum characteristics as well as $R_{n}{ }^{*}-R_{n}$ values for both tested coating systems.

In addition to it changes in the resistive properties of tested coating systems were estimated when immediately after EN measurements single frequency $(1 \mathrm{kHz})$ impedance test was performed with the use of HIOKI LCR HITESTER.

\section{RESULTS AND DISSCUSIONS}

Due to the fact that both tested coating systems after $168 \mathrm{hrs}$ of exposure to $0.05 \mathrm{M} \mathrm{NaCl}$ can be considered for rather stationary systems with barrier mechanism (with high noise impedance $Z_{n, f \rightarrow 0}$ values) only MEM curves presented here were checked because of providing a smoother version of impedance spectrum as compared to FFT curves. As can be seen from Figures 1-2 MEM impedance spectrum is for every of tested coatings different confirming by this way quite different barrier properties of tested coatings.

This fact corresponds also to quite different degree of barrier effect development because water and/or solution penetration within coating through pores and ionic pathways can be delayed and dependent on contributions from charge transfer and mass transport reactions different in tested coatings. 


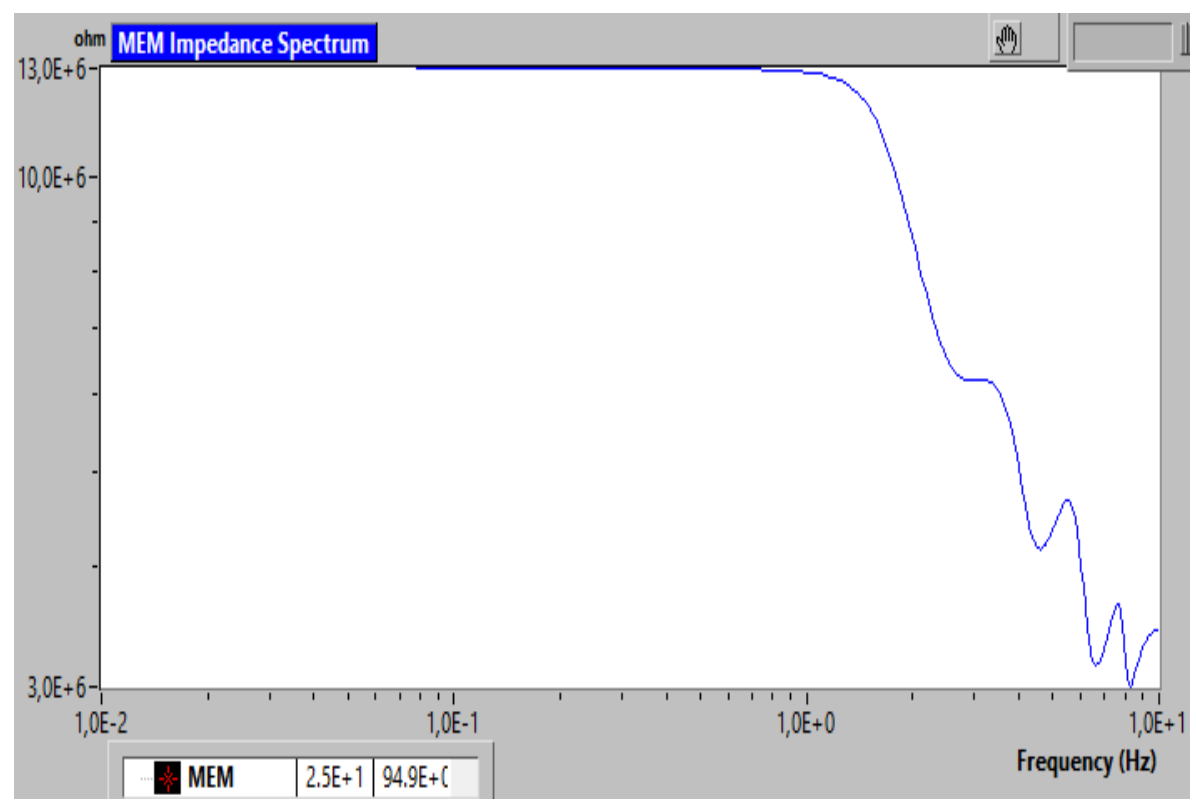

Figure 1 Noise impedance spectrum (MEM curve) for AKAl 112 after 168 hrs exposure

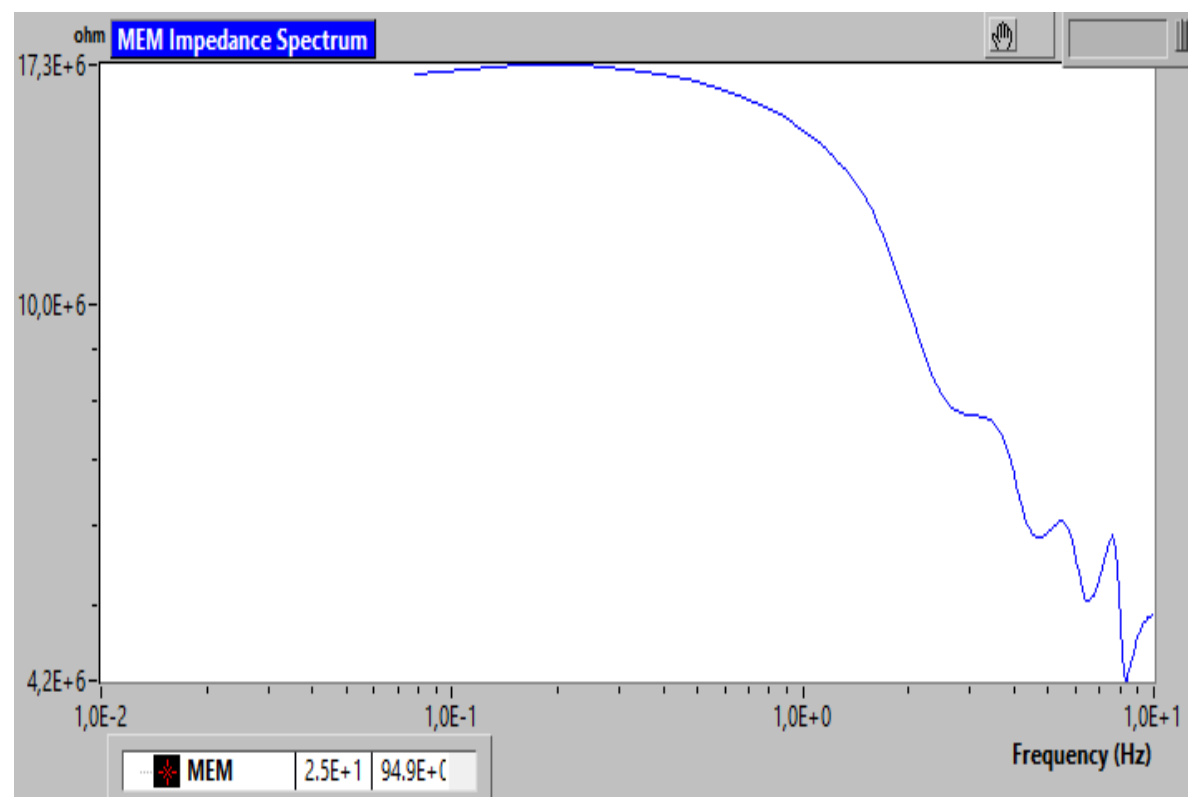

Figure 2 Noise impedance spectrum (MEM curve) for AKAl 107 after 168 hrs exposure

Considering possible interpretation of presented MEM curves according Vilche et al [6] it should be remembered the Warburg impedance $Z_{w}$ for a diffusion process in a layer of finite thickness is given by the expression

$$
Z_{w}(\omega)=R_{D O}\left(i \omega \delta^{2} / D\right)^{-0,5} \tanh \left(i \omega \delta^{2} / D\right)^{0,5}
$$

where $R_{D O}$ denotes the $\omega \rightarrow 0$ limit of $Z_{w}(\omega)$, $\delta$ is the thickness of the diffusion layer and $D$ is the diffusion coefficient.

Eq (1) assumes that a.c. diffusion layer thickness (i.e. the distance travelled by diffusion species in the low frequency oscillating perturbations) is very much less than the d.c. Nernstian diffusion layer thickness [8]. In the fact if the frequency-dependent diffusion length is defined as $\delta=\sqrt{D / \omega}$ and $s=(\delta / L)^{2}$ where $L$ is the coating 
thickness then values of $Z$ estimated by the single frequency $(1 \mathrm{kHz})$ impedance test can be used to substitute values of $Z_{w_{\infty}}$ when the tanh term approaches unity and $Z_{w}=R_{D o} \sqrt{i s}$. The same test can also provide values of $R_{c}$ involved in Vilche et al model.

Considering these suggestions is possible to check how accurately MEM impedance spectrum can be reproduced according to the following expressions

$$
[Z(\omega)]^{-1}=Y_{0} \sqrt{i \omega}+\frac{R_{C}+R_{D O}(\delta / L) \sqrt{i \omega} \tanh (\delta / L) \sqrt{i \omega}+\left(R_{n}^{*}-R_{n}\right)}{\left[R_{C}+R_{D O}(\delta / L) \sqrt{i \omega} \tanh (\delta / L) \sqrt{i \omega}\right]\left(R_{n}^{*}-R_{n}\right)}
$$

where

$$
Y_{0}=\frac{1}{\sigma \sqrt{2}}
$$

whereas

$$
\sigma=\frac{R T}{n^{2} F^{2} A \sqrt{2}}\left(\frac{1}{D_{O 2}^{0.5} c_{O 2}}\right)
$$

where $\mathrm{n}=$ number of electrons in ORR, $\mathrm{A}=$ delaminated area, Do2 = diffusion coefficient of oxygen in the polymeric coating and $\mathrm{CO}_{2}=$ solubility of oxygen inside the polymer at temperature $\mathrm{T}$.

For practical use of Eq. (2) should be remembered that implementation of $R_{n}{ }^{*}-R_{n}$ value means possibility of development situation when $R_{n}{ }^{*}-R_{n}<0$. In this case the defect developed locally at the coating/steel interface is not galvanically protected by sufficient amount of $\mathrm{Zn}$ particles around the defect. Opposite to it when still sufficient amount of $\mathrm{Zn}$ particles remains at the coating/steel interface available for local galvanic protection of a defect developed locally, then $\left|R_{n}{ }^{*}-R_{n}\right|$ value instead of $\left(R_{n}{ }^{*}-R_{n}\right)$ value should be used in Eq. (2).

It should be noted the relative values of $R_{D O}$ and $\sigma$ determine whether the system is under charge-transfer control for $\mathrm{R}_{\mathrm{DO}} / \sigma>10$ or under diffusion control if $\mathrm{R}_{\mathrm{DO}} / \sigma<0.1$ [9]. For tested coating systems in the end of 168 hrs exposure in $0.05 \mathrm{M} \mathrm{NaCl}$ values of $\mathrm{D}_{\mathrm{O} 2}=1.18 \mathrm{E}-10 \mathrm{~cm}^{2} \mathrm{~s}^{-1}$ and $\mathrm{CO}_{2}=4.02 \mathrm{E}-8 \mathrm{~mol} / \mathrm{cm}^{3}$ were found [10]. As compared with $\mathrm{D}_{\mathrm{O} 2}$ and $\mathrm{CO}_{2}$ values reported before for non-pigmented polymeric coating in $0.5 \mathrm{M} \mathrm{NaCl}$ [11] these values are much smaller due to suggested better barrier properties of tested coatings. By this way for known values of $\mathrm{D}_{\mathrm{O} 2}$ and $\mathrm{CO}_{2}$ delaminated area size for given type of coating in the end of the test can be calculated using fitting parameter $Y_{0}$ values estimated for MEM curves in Figures 1-2. In Table 2 are values of parameters involved in Vilche et al model (with the use of $R_{n}{ }^{*}-R_{n}$ in terms including $R_{A}$ ) for tested coating systems.

Table 2 Summary of parameters involved in Vilche et al model estimated for tested coating systems in the end of $168 \mathrm{hrs}$ exposure

\begin{tabular}{|c|c|c|c|c|c|c|}
\hline Sample & $\boldsymbol{\delta}(\mathbf{c m})$ & $\mathbf{R}_{\mathrm{DO}}(\boldsymbol{\Omega})$ & $\mathbf{R}_{\mathbf{c}}(\boldsymbol{\Omega})$ & $\mathbf{R}_{\mathbf{n}}{ }^{*}-\mathbf{R}_{\mathbf{n}}(\boldsymbol{\Omega})$ & $\mathbf{Y}_{\mathbf{0}}\left(\mathbf{s}^{\mathbf{0}, 5} \mathbf{\Omega}\right)$ & $\mathbf{A}\left(\mathbf{c m}^{2}\right)$ \\
\hline AKAl 112 & $1.062 \mathrm{E}-03$ & $13.0 \mathrm{E}+06$ & $18.227 \mathrm{E}+06$ & $12.812 \mathrm{E}+06$ & $4.646 \mathrm{E}-08$ & $5.753 \mathrm{E}-05$ \\
\hline AKAl 107 & $7.610 \mathrm{E}-04$ & $17.3 \mathrm{E}+06$ & $13.149 \mathrm{E}+06$ & $-5.305 \mathrm{E}+06$ & $6.847 \mathrm{E}-08$ & $2.597 \mathrm{E}-04$ \\
\hline
\end{tabular}

As the loss of adhesion is directly linked to the reduction of oxygen at the steel/coating interface this approach can be used for determination of delaminated area size. Considering of $168 \mathrm{hrs}$ exposure to $0.05 \mathrm{M} \mathrm{NaCl}$ in relation to the formulation and the structure of tested coatings (see Figure $\mathbf{3}$ and $\mathbf{4}$ ) it is clear the Al particles in combination with inorganic pigment Syloid can reduce cathodic delamination to minimum by preventing the transport of oxygen and water through coating. The tortuous detours provided by flake shaped Al pigment particles seems to increase the diffusion path and decrease the cross-section area through which diffusion occurs. It should be noticed the high number of Al particles in the coating AKAl 112 can improve coating delamination resistance also due to possible decrease of chemical activity of $Z n$ in the coating/steel interface. For this region in the end of experiment a considerable reservoir of burried $\mathrm{Zn}$ remains available for local galvanic protection should a defect developed locally to expose an isolated Zn particle (see Figure 3). 


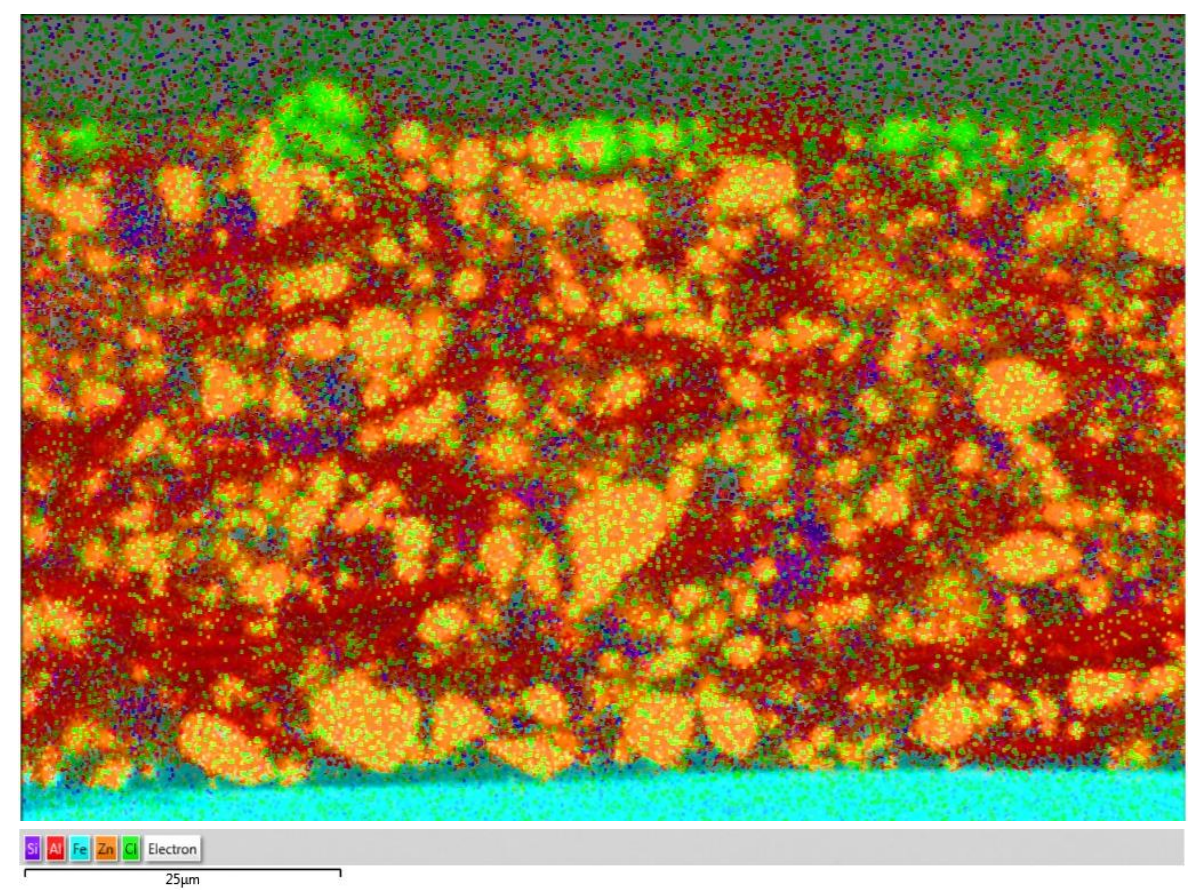

Figure 3 EDX mapping and structure (SEM-SE image) of cross-section for AKAl 112

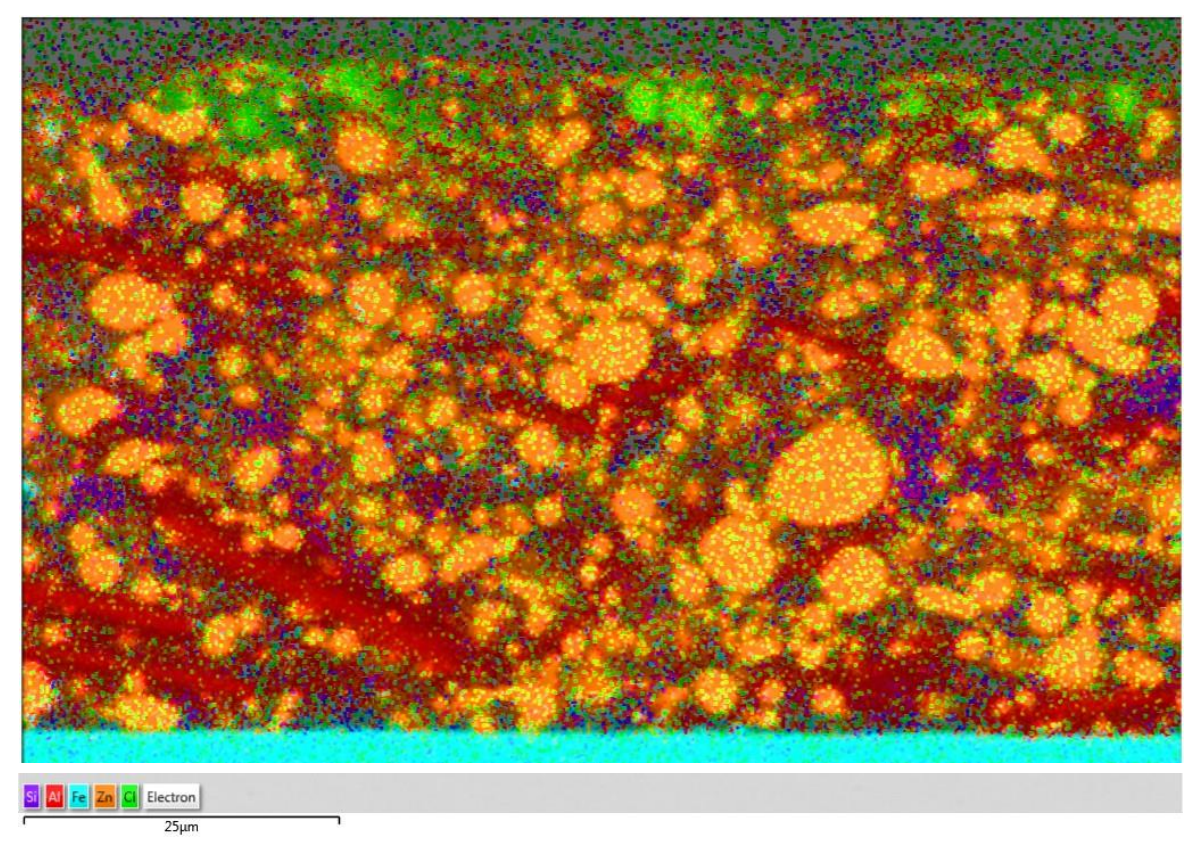

Figure 4 EDX mapping and structure (SEM-SE image) of cross-section for AKAl 107

\section{CONCLUSIONS}

A new approach for the use of ENA in combination with the single frequency $(1 \mathrm{kHz})$ impedance test measurements has been proposed and utilized for the noise impedance spectrum interpretation. Through this new approach the role of various parameters on the delaminated area size has been investigated to achieve better understanding of barrier mechanism and help optimizing coating formulation to be ensuring resistance to cathodic delamination. 


\section{ACKNOWLEDGEMENTS}

The study was performed and paper was written with support of project MPO - DKRVO 8/2018.

\section{REFERENCES}

[1] EREMIAS B., TUREK L. Application of ENA to investigate the effect of partial substitution of $\mathrm{Zn}$ by $\mathrm{Al}$ in epoxy coatings on delamination kinetics of underlaying steel: In METAL 2018: 27th International Conference on Metallurgy and Materials. Ostrava: TANGER, 2018, pp. 1091-1096.

[2] EREMIAS B., TUREK L., MINDOS L., HOCHMANNOVA L. ENA study of possible improvement in formulation design practices for optimized performance of $\mathrm{Zn}$ and Al pigmented epoxy coatings: In METAL 2019: 28 th International Conference on Metallurgy and Materials. Ostrava: TANGER, 2019, pp. 1010-1015.

[3] EREMIAS B., MINDOS L., TUREK L., The application of ENA for comparison of protective performance of ZRP modified by combination of $Z$ n dust with aluminium or carbon type fillers. In: METAL 2020: 29th International Conference on Metallurgy and Materials. Ostrava: TANGER, 2020, pp. 683 - 688.

[4] KENDIG M., SCULLY J. Basic Aspects of Electrochemical Impedance Application for the Life Prediction of Organic Coating on Metals. In: Corrosion. 1990, vol. 46, pp. 22-29.

[5] BIERWAGEN, G.P., BALBYSHEV, V., MILLS, D., TALLMAN, D. In Proceedings of the Symposium on Advances in Corrosion Protection by Organic Coating II: Spec. Publication of the Electrochem. Society, 1995, pp. 69 - 81.

[6] VILCHE, J.R., BUCHARSKY, L.C., GIUDICE, C.A., Application of EIS and SEM to evaluate the influence of pigment shape and content in ZRP formulation on the corrosion prevention of Naval steel: Corrosion Science. 2002, vol. 44, pp. $1287-1309$.

[7] EREMIAS B., MINDOS L., TUREK L. Possibilities of ENM to evaluate anti-corrosion performance of new types of zinc rich epoxy paints in relation to ZRP formulations. In: EUROCORR 2013. Frankfurt: DECHEMA, 2013, pp. 217.

[8] WALTER G.W. Application of impedance measurements to study performance of painted metals in aggressive solutions. J. Electroanal. Chem. 1981, vol. 118, is. 10, pp. $259-273$.

[9] SEKINE, I., SAKAGUCHI, K., YUASA, M., Estimation and prediction of degradation of coating films by frequency at maximum phase angle. J. Coating Tech. 1992, vol. 64, no. 810, pp. $45-49$.

[10] EREMIAS B., Unpublished results.

[11] LENG A., STRECKEL, H., HOFMANN, K., STRATMANN, M., The delamination of polymeric coatings from steel, Part 3: effect of the oxygen partial pressure on the delamination reaction and current distribution at the metal/polymer interface. Corrosion Science. 1999, vol. 41, pp. $599-620$. 